\title{
Development and Evaluation of Synthetic Antigenic Peptides for Diagnosis of Infectious Bursal Disease
}

\author{
S. Upadhyay ${ }^{1 *}$, V. Umapathi ${ }^{2}$ and B.K. Sarkar ${ }^{3}$ \\ ${ }^{1}$ AICRP on PHET, Department of Livestock Products Technology, College of Veterinary \\ Science, Assam Agricultural University, Khanapara, Guwahati, Assam, India \\ ${ }^{2}$ Department of Veterinary Physiology and Biochemistry, GB Pant University of Agriculture \\ and Technology, Pantnagar, Uttarakhand, India \\ ${ }^{3}$ Department of LPT, College of Veterinary Sciences and Animal Husbandry, $R$ K Nagar, \\ Tripura, India \\ *Corresponding author
}

\section{A B S T R A C T}

\begin{abstract}
Infectious Bursal Disease (IBD) is an economically important and contagious viral disease of poultry. An attempt was made for development of a synthetic peptide based diagnostic reagent. Cell culture adapted viral antigen was prepared by successful passage on CEF and then ultracentrifugation to get partially purified virus. Confirmation of the virus in was done by RT- PCR. The antigen was then used for the production of hyper immune sera in rabbits. Sera samples were also collected from known IBD vaccinated and non-vaccinated birds. Four different sequences were selected based on antigenic determinant analysis using sequence data available on Gene bank. Four MAPs, M1, M2, M3 and M4 were synthesized based on these sequences using FMOC chemistry. These peptides were then screened for their reactivity with the hyperimmune sera using indirect ELISA. Although all the peptides showed positive reaction, peptide M3 showed the highest reactivity. Screening was also done with the randomly selected 33 known bird sera for their reactivity pattern. It was found that all the peptides consistently differentiated positive and negative sera samples accordingly whether the samples were obtained from vaccinated or unvaccinated birds. This study offers a technology on designing of IBD virus specific synthetic peptides as diagnostic reagents for their use in IBD diagnosis.
\end{abstract}

\section{Introduction}

Infectious bursal_disease (IBD) is a highly contagious disease of young chickens caused by IBD virus (IBDV), characterized by immune-suppression and mortality generally at 3-5 weeks of age (Yunus et al., 2008). The reemergence of IBD particularly in last couple of decades in variant or highly virulent forms has been the cause of significant economic losses (Lukert and Saif, 2003). While tackling this dreaded virus diagnosis of the disease becomes important for which, conventional tests such agar gel precipitation test (AGPT) (Majee et al., 2003), enzyme linked immunosorbent assay (ELISA) (Wang 
et al., 2008), histopathology (HP), virus neutralization test (VNT) (El-Ebiary et al., 1997), fluorescent antibody technique (FAT) (Ide, 1975), etc., have been used. Some of these tests are lack sensitivity and time consuming. Adoption of molecular techniques have recently helped in developing more rapid and sensitive diagnostic tests viz. nucleic acid probe hybridization, RT- PCR etc. Development of new diagnostics and vaccines relies on the aspects of specificity, safety and cost factors. The tremendous advances in the development of methods for the synthesis of peptides have led to unique opportunities to apply designed synthetic peptides to diverse areas of diagnostics, vaccination and chemotherapy. Main advantage of using the synthetic peptide for such purposes are: they are safe, judiciously devoid of lethal or toxic factors unlike whole organisms, cheap, easy to store and handle and ideally suited for specific targeting, which is not possible with classical vaccines. Synthetic peptides based agents do not require cold chain, a welcoming feature for field use. Synthetic peptides have the additional advantage that relatively short stretches of amino acid sequence constituting peptide epitopes in antigen are capable of eliciting an immune response recognizing cognate sequence in parent molecule and can be selected, eliminating other epitopes potentially responsible for pathological effects due to nonspecific or undesirable stimulation. Multiple antigenic peptides (MAPs) are used in immunoassays for serodiagnosis of infectious bronchitis (Jackwood and Hilt, 1995) and infectious bursal disease (IBD) virus (Saravanan et al., 2004). However, more efforts are needed for a better and specific differential diagnostic assay. The present study was envisaged with the following objectives: i) Production of hyperimmune sera in rabbits using two types of antigen- cell culture adapted viral antigen and bursal tissue derived viral antigen ii)
Synthesis of _ MAPs corresponding to immunodominant epitopes of IBDV iii) Screening of MAPs with hyperimmune sera and IBDV positive and negative sera for their possible use as diagnostic reagents against IBDV.

\section{Materials and Methods}

\section{Preparation of antigen}

The two types of antigen used for raising hyperimmune serum were pre-confirmed Chicken Embryo Fibroblast (CEF) adapted (4th passage) UA/BZ/2 strain of the IBDV propagated up to $8^{\text {th }}$ passage and wild strain of IBDV isolated from bursal tissue during field outbreak. The CEF prepared in Roux flasks and $75 \mathrm{~cm} 2$ tissue culture flasks were infected with CEF adapted UA/Bz/2 strain of IBDV. After appearance of cytopathic effect over $70 \%$ of the monolayer, the culture flasks were frozen. A total of $1000 \mathrm{ml}$ tissue culture fluid was prepared by freeze-thawing three times quickly and the tissue culture fluid was stored at $-20^{\circ} \mathrm{C}$ for further use of purification and characterization. The culture supernatant suspension stored in $-20^{\circ} \mathrm{C}$ was rapidly freeze-thawed thrice.

\section{Isolation of viral RNA and quantification}

The total cellular RNA including viral RNA was isolated from cell culture suspension (Chomocznski and Sacchi, 1987 and Sambrook et al., 1989) with slight modifications. Media was discarded and cells were washed with $5-8 \mathrm{ml}$ of ice cold phosphate buffer saline per $75 \mathrm{~cm}^{2}$ culture flask. Thereafter, monolayer was detached from surface of tissue culture flask by treating the culture with $5 \mathrm{ml}$ of MLS. Similarly bursal suspension was also treated with MLS. After thorough mixing culture as well as the bursal suspension was transferred to the DEPC treated oakridge tube and subjected to 
sonication for 30 s of 10 cycles with 15 s pause in each cycle. Then kept at room temperature for 15 minutes and transferred to the ependroff tubes of $1 \mathrm{ml}$ each.

The RNA was then isolated using phenol chloroform extraction procedure. Lastly, RNA pellet was dissolved in $100 \mu$ l of DEPC treated water and incubated for 10-15 minutes at $55^{\circ} \mathrm{C}$ to ensure complete solubilisation of RNA and stored at $-20^{\circ} \mathrm{C}$. Total RNA isolated from culture was quantified using UV/ VIS spectrophotometer and reading absorbance at $260 \mathrm{~nm}$.

\section{Confirmation of viral RNA}

In order to check the presence of viral RNA, RT-PCR was performed using purified primer set $(23$ mer) for amplification of $248 \mathrm{bp}$ fragment of hypervariable region of $\mathrm{vp} 2$ gene of IBDV(Ikuta et al., 2001).

Forward primer 5' GTA ACA ATC ACA CTG TTC TCA GC 3’ 804-826

Reverse primer 5' GAT GTG ATT GGC TGG GTT ATC TC 3' 1029-1051

The reaction conditions for amplifying the $248 \mathrm{bp}$ fragment of vp2 gene of IBDV was standardized with RT-PCR with the following reaction mixture.

cDNA :

Forward primer:

Reverse primer:

$10 \mathrm{mM}$ dNTP mix:

10X reaction buffer:

Nuclease free water:

Taq polymerase:

The cDNA was denatured by keeping the mixture at $98^{\circ} \mathrm{C}$ for 4 minutes. Then the amplification of vp2 gene was done for 30 cycles at $94^{\circ} \mathrm{C}$ for 1 minute, $55^{\circ} \mathrm{C}$ for 1 minute (vp2 gene), $72{ }^{\circ} \mathrm{C}$ for 1 minute, followed by final extension at $72^{\circ} \mathrm{C}$ for 5 minutes. Once the cycles were completed the reaction mixture was checked for amplification by electrophoresis in ethidium bromide stained $1.5 \%$ agarose gel at 50 volts and documented in gel documentation system.

\section{Raising of hyperimmune serum}

Hyperimmune serum against cell culture purified virus as well as the purified bursal suspension $(10 \% \mathrm{w} / \mathrm{v})$ of IBDV was raised in 6 months old rabbits divided into 3 groups (2each) in 5 doses as described by Hussain $e t$ al., (2004) with slight modifications. For the initial dose $50 \mu \mathrm{g}(0.2 \mathrm{ml})$ purified cell culture adapted viral antigen was emulsified with equal volume of Freund's complete adjuvant and injected in rabbit by s/c route. Booster doses were given with equal volume of antigen and Freund's incomplete adjuvant at 7 th, $14^{\text {th }}, 28$ th and 35thday. After 7 days of each booster, rabbits were bled and serum was separated and stored at $-20^{\circ} \mathrm{C}$ for further use.

\section{Prediction of antigenic determinants}

Sequence data available on Genbank were used for sequence information analysis. The sequences selected were from the VP2, VP3 and VP4 region of IBDV. Four different sequence were selected for the synthesis of peptides.

\section{Synthesis of multiple antigenic peptides}

Direct FMOC (9-Fluorenyl methoxy carbonyl) solid phase peptide synthesis was followed in this study by employing branching of lysine on rink amide resin. Four different types of MAPs were synthesizedM1 of 11 mer, M2 of 13 mer, M3 of 21 mer and M4 of 22 mer. 


\section{Preparation of FMOC-Ala-rink amide}

DMF (dimethyl-formamide) was added to rink amide resin and was kept in Merrifield vessel for overnight at room temperature to swell the resin. FMOC-Ala, DIEA, HOBt (3 equivalents) and HBTU (2.9 equivalents) in amount to that of resin's loading efficiency were added to the swollen resin. The contents were mixed thoroughly and kept under constant shaking for overnight. Resin was washed three times with DMF and then checked for coupling of alanine to resin.

\section{Removal of FMOC group from FMOC- Ala-rink amide}

After washing the resin with DMF resin was treated with $20 \%$ piperidine for 10 minutes and 25 minutes consecutively. The beads were then washed twice with DMF and DMA (N, N-dimethylacetamide) and once with DCM (Methylne dichloride). The resin was then dried by vaccum.

Preparation of Di-FMOC-Lys-Ala- rink amide

The lysine was attached to the FMOC-AlaResin following same procedure as for alanine.

\section{Preparation of branched lysine MAP core matrix}

The FMOC group from the Di-FMOC-Lys attached to Ala-rink amide was removed by deprotection with $20 \%$ piperidine in DMF as described before. Coupling of di-FMOC-Lys to Lys-Ala-rink amide was carried out by adding six milliequivalent each of Di-FMOClys, HBTU and HOBt. The vessel was kept in orbital shaker at $160 \mathrm{rpm}$ for $2 \mathrm{hrs}$ at RT for proper mixing. Resultant product was the MAP core with 4 dendritic arms.

\section{Preparation of MAPs}

The MAPs were prepared as per the method of Tam (1988) by coupling 12 equivalent of FMOC amino acid and Hobt and 11.6 equivalent of HBTU and HOBt using DMF as Solvent. The above solution was mixed and the vessel was kept in orbital shaker for $2 \mathrm{hrs}$ at $160 \mathrm{rpm}$ and room temperature. After $2 \mathrm{hrs}$ the resin was then washed with DMF thrice and was checked for coupling of amino acid. Coupling procedure used and methodology adopted provide almost $100 \%$ coupling although its success was checked by Kaiser test.

\section{Acetylation of the synthesized MAP}

The synthesized MAPs were acetylated before cleavage from the resin. The procedure followed is as follows. The FMOC group of the last amino acid attached was deprotected by $20 \%$ piperadine in DMF. The resin was then washed twice with DMF and DMA and once with DCM. The resin was then checked for deprotection of FMOC group by Kaiser test. The acetylation mixture (DMF:Acetic Anhydride: N,N-diisopropylethylamine = 193:6:1) was then added to the resin. The vessel was then kept for 5 hours in orbital shaker at $160 \mathrm{rpm}$ at room temperature. The resin was then checked for coupling by Kaiser test and was transferred to the eppendorf tube. Then it was dried by keeping in vacuum desiccator for overnight.

Final cleavage of MAPs from rink amide resin support

The cleavage mixture with following composition was added to the dried resin per $100 \mathrm{mg}$ resin.

$\begin{array}{lr}\text { TFA } & 850 \mu \mathrm{l} \\ \text { Thioanisole } & 50 \mu \mathrm{l} \\ \text { EDTA } & 25 \mu \mathrm{l}\end{array}$




$\begin{array}{lc}\text { Phenol } & 50 \mathrm{mg} \\ \text { TIS }(1 \%) & 20 \mu \mathrm{l} \\ \text { Water } & 50 \mu \mathrm{l}\end{array}$

The tubes were covered and were shaken for $5 \mathrm{hrs}$ at RT and the supernatant was collected in separate tubes. The supernatant was then concentrated by keeping in DNA vac concentrator (Savant, India) for 5 hours. The MAPs were precipitated with chilled diethyl ether and washed 7 to 8 time with the diethyl ether and finally vacuum dried to get white crystalline powder. When used, the peptides were dissolved in HPLC grade water to get a solution of $2 \mathrm{mg} / \mathrm{ml}$ concentration.

The peptides were then screened for reactivity with hyperimmune sera of rabbits as well as the sera collected from vaccinated and unvaccinated birds.

\section{Screening of hyperimmune sera raised in rabbits for IBDV antibodies with indirect ELISA}

ELISA plate wells were coated with the four synthesized MAPs as antigen at the rate of $4 \mu \mathrm{g}$ per well in $100 \mu \mathrm{l}$ of coating buffer (Carbonate-bicarbonate buffer, $\mathrm{pH}$ 9.6) at $37^{\circ} \mathrm{C}$ for $2 \mathrm{hrs}$. Unbound antigens were removed by washing the ELISA plate 3 times with PBS-T (PBS+0.05\% Tween 20). The remaining free sites on the well were blocked by adding $300 \mu \mathrm{l}$ of blocking buffer (2\% BSA in PBS) for 2 hours at $37^{\circ} \mathrm{C}$. Blocking buffer was removed and plates were washed 5 times with PBS-T.

Sera samples having highest titre (28 Day after immunization_sera) of each of the four hyperimmunised rabbits as well as the control in 1:100 dilutions (After standardization) were added to each well in $100 \mu 1$ of blocking buffer and incubated at $37^{\circ} \mathrm{C}$ for 2 hours. Plate was then washed 5 times with PBS-T to remove excess antibodies. Goat anti-rabbit
IgG HRP conjugate (1:30000) was added to each well in $100 \mu l$ of blocking buffer and incubated at $37^{\circ} \mathrm{C}$ for $1 \mathrm{hr}$. Wells were washed 5 times with PBS-T to remove unreacted conjugate. Then $100 \mu \mathrm{l}$ of OPD (ophenylenediamine dihydrochloride)_substrate solution was added to each well and incubated for $15 \mathrm{~min}$ at $37^{\circ} \mathrm{C}$ in dark. After development of colour, $50 \mu 1$ of stopping solution was added and OD was read at $490 \mathrm{~nm}$.

\section{Screening of IBD vaccinated and IBD unvaccinated birds for IBDV antibodies with indirect ELISA}

The ELISA tests were carried out as described above for the screening of IBDV antibodies for reactivity with the multiple antigenic peptide. The serum was diluted in the ratio of 1:100 and the conjugate was used in the ratio of $1: 30000$.

\section{Results and Discussion}

The total protein content of purified cell culture passage virus sample and the bursal tissue derived viral suspension was found to be $1.967 \mathrm{mg}$ and $17.57 \mathrm{mg}$ as observed by spectrophotometer specificity of RT-PCR for IBDV was already compared with other viruses (Lee et al., 1994). IBDV in bursa could be detected for a longer period after infection as could be evidenced from comparison of conventional assays and RTPCR for IBDV detection in the bursa of fabricius of infected birds by Abdul-Alim and Saif, (2001). RT-PCR was performed for viral RNA prepared from infected bursa viz. and from CEF infected with strain UA/BZ-2. RTPCR using specific primers resulted in amplification of 248bp vp2 hyper variable region of IBDV.RT-PCR amplified $248 \mathrm{bp}$ fragment bands of field isolate as well as the cell culture adapted strain were observed. (Fig. 1) 
Fig.1 Agarose gel showing the PCR amplified 248 bp fragment of VP2 gene in bursa derived viral antigen (B) and cell culture adapted viral antigen (C)

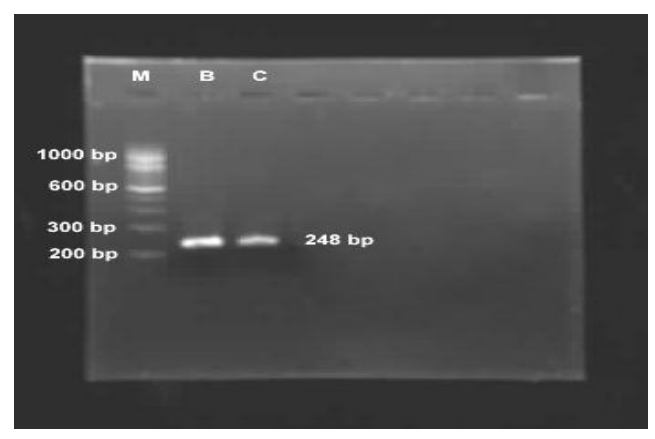

Fig.2 The reactivity of four different antigenic peptides with the sera samples of three different groups of rabbits- Series R1-rabbits injected with bursal tissue derived antigen, Series R2rabbits injected with cell culture adapted antigen and Series $\mathrm{C}$-control group of rabbits. Both the groups (R1 and R2) have shown reactivity with all the four antigenic peptides and with M3 it was found to be maximum. The cut off value was calculated as OD492 value of control added to three times standard deviation of control group

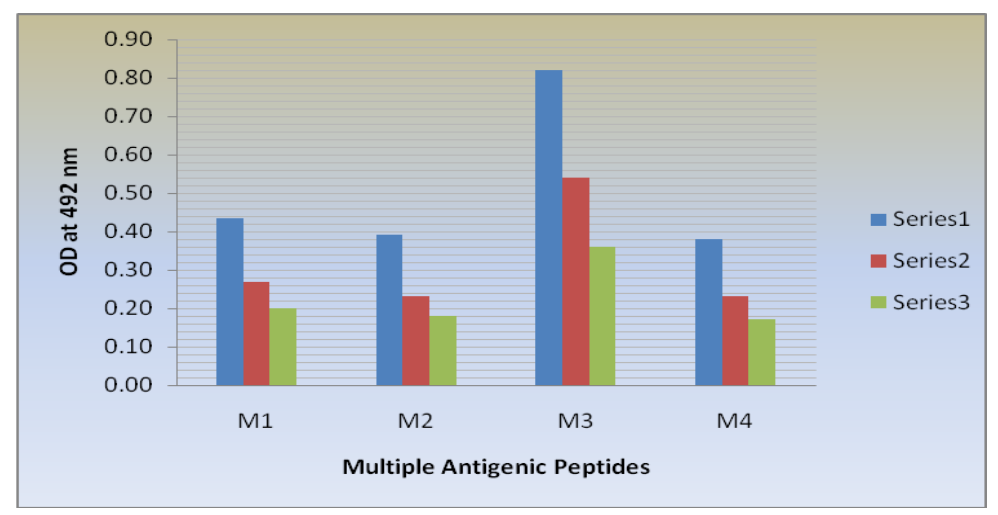

Fig.3 The reactivity of peptide M1 with the 33 vaccinated as well as the unvaccinated birds sera sample. The red line is the cut off value and the samples above the line are considered as positive while those below the line are considered as negative. The cut value is calculated by adding 3 times of standard deviation with the average O.D. of negative sera

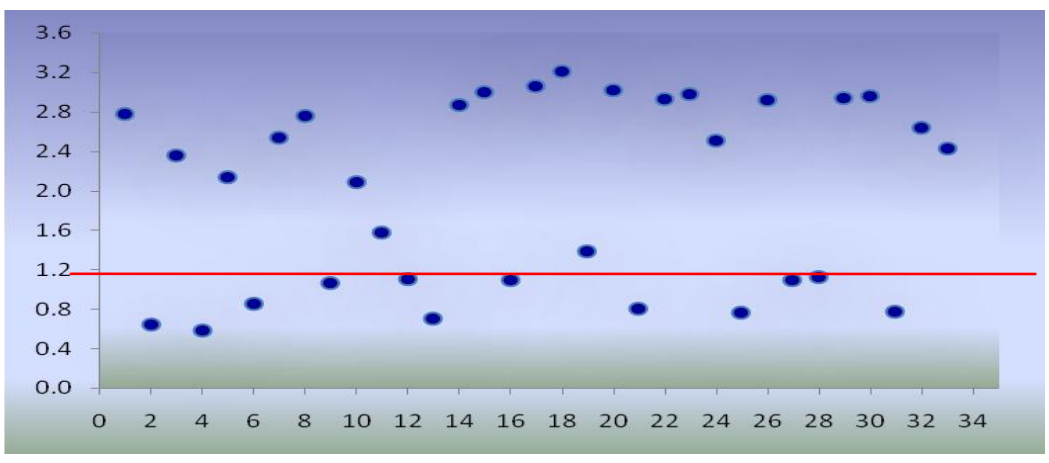


Fig.4 The reactivity of peptide M2 with the 33 vaccinated as well as the unvaccinated birds sera sample. The red line is the cut off value and the samples above the line are considered as positive while those below the line are considered as negative. The cut value is calculated by adding 3 times of standard deviation with the average O.D. of negative sera

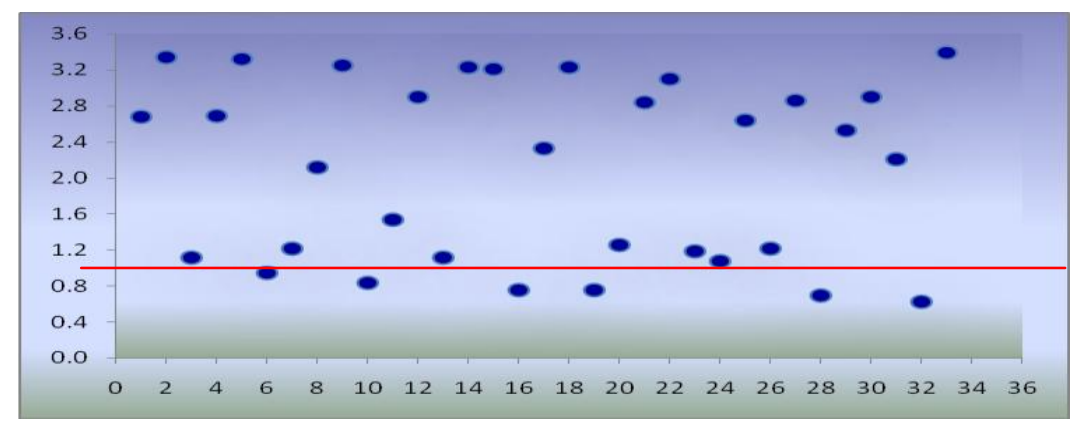

Fig.5 The reactivity of peptide M3 with the 33 vaccinated as well as the unvaccinated birds sera sample. The red line is the cut off value and the samples above the line are considered as positive while those below the line are considered as negative. The cut value is calculated by adding 3 times of standard deviation with the average O.D. of negative sera

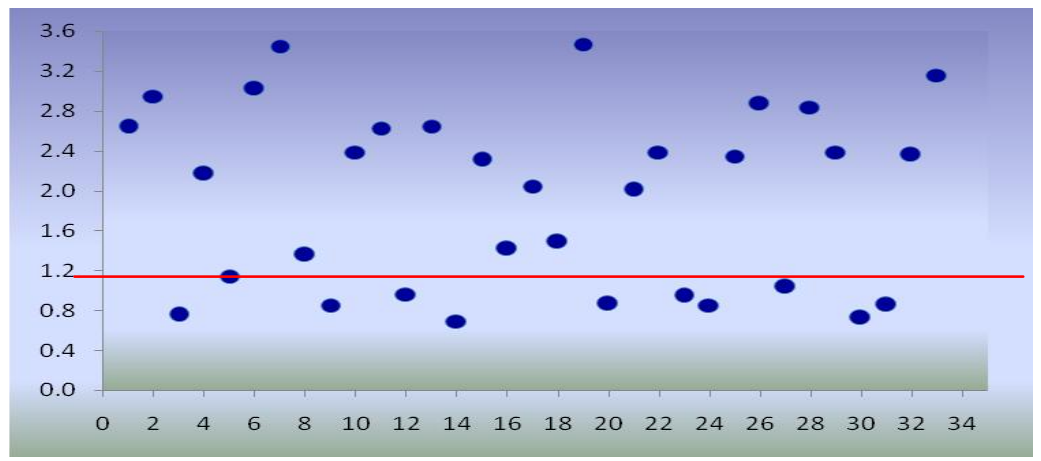

Fig.6 The reactivity of peptide M4 with the 33 vaccinated as well as the unvaccinated birds sera sample. The red line is the cut off value and the samples above the line are considered as positive while those below the line are considered as negative. The cut off value is calculated by adding 3 times of standard deviation with the average O.D. of negative sera

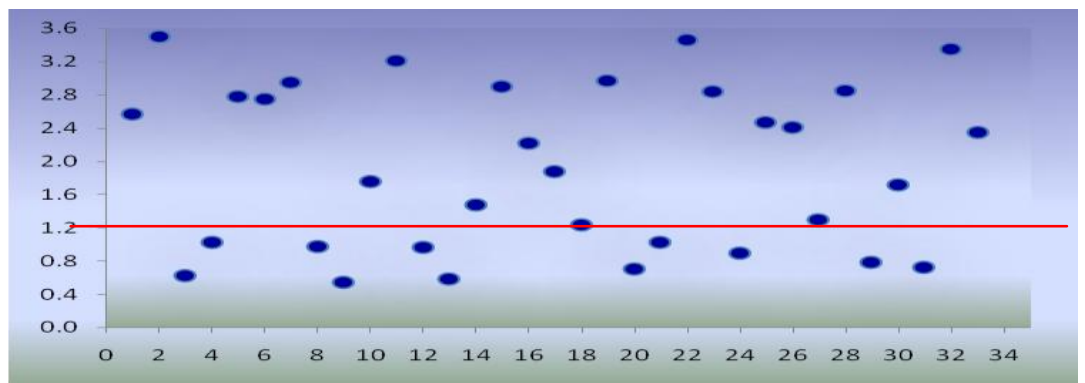


Hyperimmune serum was raised against the purified virus by immunization in adult rabbits. The rabbits were bled after 7 days of final dose and the serum was checked for antibody titre using ELISA with the confirmed antigen and was found to be 1:32, 1:64, 1:256, 1:256 for cell culture adapted viral antigen and 1:64 for bursal tissue derived antigen at 7,14,28,35 and 42 days respectively.

MAPs were synthesized on rink amides resin using the method of FMOC chemistry (Francis et al., 1991). On resin four arms of lysine were generated by coupling DL FMOC-Lys-OH using HBTU and HOBT coupling. Several studies have been performed to determine the optimum number of copies of dendritic arms of a MAP system (Tam and Zabala, 1989; Tam and LU, 1989; Francis et al., 1991). It was found that four copies of antigen were found to be successful for diagnostic purpose (Shrivastava et al., 2006). Therefore, in this study, four copies of peptide were synthesized for each peptide sequence in MAP format. About $100 \mathrm{mg}$ of resin was used for each MAP synthesis. The MAPs so synthesized on resin were cleaved by using cleavage mixture comprising of TFA (Trifluoroacetic acid) phenol, TIS (Triisopropylsilane) and thioanisole as used by Shrivastava et al., (2006) and was then precipitated using cold diethyl ether. The MAPs were then dried and were dissolved in HPLC grade water to make a concentration of $2 \mathrm{mg} / \mathrm{ml}$ before use The 28th day sera sample was collected from both groups of rabbit and were tested using ELISA along with the control (normal rabbit sera) for reactivity against different MAPs The 28th day sera were tested because it was showing the highest titre as compared to other sera samples. The mean O.D490 values were recorded for each sample and standard deviation was calculated. The ELISA cut off value was derived as mean O.D490 of negative samples added to three times standard deviation. The samples having O.D490 value more than the cut off value were taken as positive. Out of four MAPs, M3 showed highest reactivity with all hyperimmune sera as well as positive sera samples (Fig. 2). A total of 250 sera samples were collected from vaccinated and nonvaccinated birds from Instructional Poultry Farm (IPF) of GBPUA\&T, Pantnagar. Around 15 per cent (33 samples) were randomly selected and tested by ELISA using four different antigenic peptides. The mean O.D490 values were recorded for each sample and standard deviation was calculated. The ELISA cut off value was calculated as mean O.D490 of negative samples added to three times standard deviation. The samples having O.D490 value more than the cut off value were taken as positive. Out of twenty sera samples taken randomly from IBD vaccinated birds, all have shown positive ELISA signal indicating the presence of anti IBDV antibody. The distribution of positive and negative sera samples tested by ELISA is shown by Scatter Plot (Fig. 3, 4, 5, 6).

Similar observations were reported by Saravanan et al., (2004), against the different antigenic peptide synthesized for IBD. Dechamma et al., (1998) and Srivastava et al., (2006) also reported high reactivity with the different antigenic peptides against PPRV(peste des petits ruminants virus).

In conclusion the reactivity of MAPs with the hyperimmune sera and the IBDV positive sera established beyond doubt that the IBDV antibodies present in both the hyperimmune as well as the sera from IBDV vaccinated birds are finding epitope of IBDV native antigen in the MAPs. The present work offers a technological potential of designing the selected MAPs for their use as diagnostics against IBDV. 


\section{References}

Abdul-Alim, G.A. and Saif, Y.M. (2001). Immunogenicity and antigenicity of very virulent strains of infectious bursal disease viruses. Avian Dis., 45: 92-101.

Chomczynski, P. and Sacchi, N. (1987). Single step method of RNA isolation by acid guanidium thiocyanate phenol chloroform extraction. Analytical Biochemistry, 162: 156-159.

Dechamma, H.J., Dighe, V. and Kumar C.A. (2006). Identification of T-helper and linear B epitope in the hypervariable region of nucleocapsid protein of PPRV and its use in the development of specific antibodies to detect viral antigen. Vet Microbiol., 118:201-11.

EL-Ebiary, E.A.; Madhy, S.S. and Khodier, M.H. (1997). Trials of using cell cultures for evaluation of IBDV vaccines in Egypt. Assiut Veterinary Medical Journal. 36:105-123.

Francis M.J., Hastings G.Z., Brown F., Mc Dermed J., Lu Y.A., Tam J.P. (1991). Immunological evaluation of the multiple antigen peptide(MAP) system using the major immunogenic site of foot and mouth disease virus. Immunology, 73: 249-254.

Hussain, I., Russel, M. H. and Mehmood M. S. (2004). production of hyper immune serum against infectious bursal disease virus in rabbits. Pakistan Vet. J., 24(4): 179-183.

Ide, P.R. (1975). A comparison of gel diffusion, fluorescent antibody and virus isolation methods in experimental and natural cases of infectious bursal disease. Canadian Journal of Comperative Medicine, 39: 183-190.

Ikuta, N., El-Attrache, J., Villegas, P., Garcia, E. M., Lunge, V. R., Fonseca, A. S., Oliveira, C. and Marques, E. K.
(2001). Molecular characterization of Brazilian infectious bursal disease viruses. Avian Dis., 45: 297-30.

Jackwood, M.W. and Hilt, D.A. (1995). Production and immunogenicity of multiple antigenic peptide MAP constructs derived from the $\mathrm{S} 1$ glycoproteino of infectious bronchitis virus (IBV). Adv Exp Med Biol., 380: 213-219.

Lee, L.H., Ting, L.J., Shein, J.H. and Shieh, H.K. (1994). Single tube, noninterrupted reverse transcriptionPCR for detection of infectious bursal disease virus. J. Clin. Microbiol., 32: 1268-1272.

Lukert, P. D. and Saif, Y. M. (2003). Infectious bursal disease. In: Diseases of Poultry. 11th Ed., B. W. Calnek (ed.) Iowa State University Press, Ames, Iowa, USA. pp: 161-179.

Majee, S.B.; Darban, G.S.; Sherikar, A.A.; Das, A.M. and Sahare, A.M. (2003). Isolation and identification of Newcastle disease virus and infectious bursal disease virus from Konkan region of Maharastra. Indian Veterinary Journal, 80: 601-603.

Marquardt, W., Johnson, R.B., W.F. and Schlotthober, B.A. (1980). An indirect enzyme linked immunosorbent assay (ELISA) for measuring antibodies in chicken infected with infectious bursal disease virus. Avian. Dis., 24: 375-385.

Sambrook, J., Fritsch, E.F. and Maniatis, T. (1989). Molecular Cloning, A laboratory manual, 2nd ed. Cold Spring Harbor Laboratory Press, Cold Spring Harbor, N.Y

Saravanan, P. and Kumar, S. (2009). Diagnostic and immunoprophylactic applications of synthetic peptides in veterinary microbiology. Microbiology research, (1): E1.

Saravanan, P., Kumar, S. and Kataria, J.M. 
(2004). Use of multiple antigenic related to antigenic determinents of infectious disease virus (IBD) for detection of anti-IBDV-Specific antibody in ELISA-quantative comparison with naïve antigen for their use in sero diagnosis. $J$. Immunol Methods., 293: 61-70.

Saravanan, P., Kumar, S. and Kataria, J.M. (2004). Use of multiple antigenic peptides related to antigenic determinants of infectious bursal disease virus (IBDV) for detection of anti-IBDV- specific antibody in ELISA-quantitative comparison with native antigen for their use in serodiagnosis. J. Immunol. Methods, 293: 61-70.

Saravanan, P., Shrivastava, S. and kumar, S. (2009). Synthesis of highly immunogenic multiple antigenic peptides for epitops of viral antigen to use in ELISA. Int. J. Pept. Res. Ther. 15(4): 313-321

Shrivastava, S. (2006). Development of synthetic antigens for diagnosis of PPR. Ph.D thesis submitted to Deemed University, IVRI.

Tam, J.P. (1988). Synthetic peptide vaccine design: synthesis and properties of high- density multiple antigenic peptide system. Proc. Natl. Acad. Sci. U.S.A. 85, 5409-5413.

Tam, J.P. and Lu, Y.A. (1989). Vaccine engineering: enhancements of immunogenicity of synthetic peptide vaccine related to Hepatitis in chemically defined models consisting of T \& B Cell epitopes. Proc. Natl. Acad. Sci. U.S.A. 86, 9084-9088.

Umapathi, V. (2007). Characterisation of a very virulent Infectious bursal disease virus isolate adapted in chicken embryo fibroblast culture. Paper presented at XIII annual convention of the ISVIB and national symposium on 'Veterinary Biotechnology and Immunology for sustainable rural livelihood security'. At College of veterinary and animal Sciences, Pookot, Wayanad, Kerala, Feb.15-17.

Wang, M. Y., Hu, H. L., Suen, S. Y., Chiu, F. Y., Shien, J. H. and Lai, S. Y. (2008). Development of an enzyme-linked immunosorbent assay for detecting infectious bursal disease virus (IBDV) infection based on the VP3 structural protein. Veterinary Microbiology, 131: 229-236.

Yunus, A., Nasir M., Farooq U. and Bohm J. (2008). Prevalence of poultry diseases and their interaction with mycotoxicosis in district Chakwal: 1 . Effects of age and flock size. Journal of Animal and Plant Science, 18: 107113.

\section{How to cite this article:}

Upadhyay, S., V. Umapathi and Sarkar, B.K. 2020. Development and Evaluation of Synthetic Antigenic Peptides for Diagnosis of Infectious Bursal Disease. Int.J.Curr.Microbiol.App.Sci. 9(08): 3789-3798. doi: https://doi.org/10.20546/ijcmas.2020.908.437 